\title{
Effects of High Pressure Heater Splitting to Heat Economy of Double Reheat Unit
}

\author{
Silong $\mathrm{Xu}^{1}$, Jianmeng $\mathrm{Yang}^{2}$, Jian $\mathrm{Li}^{1}$, Boshuo Sun ${ }^{2, a}$ \\ ${ }^{1}$ Jiangxi Electric Power Design Institute, Nanchang,330096,China \\ ${ }^{2}$ School of Energy, Power and Mechanical Engineering, North China Electric Power University, \\ Baoding,071003,China \\ asunboshuo@126.com
}

\begin{abstract}
Keywords: double reheat unit, thermal economy calculation, unit cycle thermal efficiency, high pressure heater splitting.
\end{abstract}

\begin{abstract}
At present, mankind is faced with serious energy problems, as the energy-hungry, power energy saving is significant. Compared with the traditional single reheat unit, using secondary reheat to further improve the thermal efficiency of the unit, and meet the requirements of the unit low pressure cylinder exhaust steam eventually humidity. Double reheat power generation technology is the important technical direction to improve the efficiency of the power plant coal-fired generating units. In this paper, we researched the thermal economy calculation of double reheat units ,to single reheat unit economy calculation as the basis, adding the process of second reheat, calculated turbine internal work, boiler heat absorption and cycle thermal efficiency of double reheat units. Consider the case of the actual operation of the presence of high pressure splitting, according to the steam distribution unit matrix equation, calculated the steam distribution of different load after high pressure splitting, and calculated the corresponding cycle thermal efficiency. The results showed that in same conditions, double reheat cycle thermal efficiency was 2.26\% higher than single reheat unit, after high pressure splitting, cycle thermal efficiency increased about $10 \%$, and with load decreasing cycle thermal efficiency is declining, Effects of high pressure splitting is also reduced.
\end{abstract}

\section{Introduction}

China's energy structure determines the pattern in coal-based power generation ,and in China's coal consumption, coal consumption accounted for more than half of the total output of coal, Therefore, to reduce the energy consumption of coal-fired generating units of thermal power generation is an important task facing our country.[1] At present, the world faced with the lack of energy crisis. Mankind constantly searching for new energy sources, developing new energy sources, at the same time, we should make better use of existing valuable resources in our hands, The best use and maintain a greater level of human development, energy saving is imperative. With the increasing steam parameters, as one of ultra-supercritical units the role of double reheat unit is gradually improved . China has determined the double reheat supercritical unit to the "Twelfth Five-Year Plan" National Energy Development Project.[2] Using secondary reheat, then will further improve the efficiency of power stations, its economy as same as Integrated Gasification Combined Cycle

(IGCC) and Pressurized Fluidized Bed Combusting Combined Cycle (PFBC-CC). China's double reheat technology in its infancy, and so far there is no secondary reheat operation, In discussing the second reheat economy, the theory has done by a lot of scholars[3]-[7].In this paper, calculates the economy of $2 \times 660 \mathrm{MW}$ secondary reheat unit. Verify that the secondary reheat superiority in power generation efficiency, and discuss the influence of high pressure heater splitting on the double reheat unit cycle thermal efficiency in different conditions.

\section{Introductions of Secondary reheat economy calculation methods}

In this paper, in accordance with previous experience, add the second reheat process, as follows: 
In accordance extraction location, the turbine is divided into several small turbines, for each small turbine to get the energy and mass balance equation, Then the calculated internal work and internal work of the various small turbine that is the whole unit turbine work, equation as follows:

$$
N=\sum_{\mathrm{i}=1}^{n+1} D_{\mathrm{ti}}\left(\mathrm{h}_{i-1}-\mathrm{h}_{i i}\right)
$$

By matrix expressed:

$$
A D+Q=\tau G
$$

Where $n$ is the number of stages extraction, so there are $n+1$ small turbines. Ht is row matrix composed of enthalpy drop of every small turbine. $H_{t}=\left[h_{0}-h_{11}, h_{1}-h_{22} \cdots h_{n}-h_{n+1 n+1}\right], h_{i-1}$ is inlet enthalpy of NO. i small turbine, hii is outlet enthalpy of NO. i small turbine $(i=1 \sim n+1)$. $D_{t}$ is column matrix composed of flow of every small turbine, $\mathrm{D}_{\mathrm{t}}=\left[\mathrm{D}_{\mathrm{t} 1}, \mathrm{D}_{\mathrm{t} 2} \cdots \mathrm{D}_{\mathrm{t}(\mathrm{n}+1)}\right]^{\mathrm{T}}$. Secondary reheat unit just get through each small turbine working fluid parameters of inlet and outlet. Including the working fluid enthalpy and flow in various small turbine.

Similarly, In accordance extraction location, the boiler is divided into several small boilers, for each small boiler to establish the energy and mass balance equation, Then the calculated internal work and internal work of the various small boiler that is the whole unit boiler work, equation as follows:

$$
Q=\sum_{\mathrm{i}=1}^{n+1} D_{\mathrm{bi}}\left(\mathrm{h}_{i-1}-\mathrm{h}_{i-1, i-1}\right)+\sum_{\mathrm{i}=1}^{n+1} Q_{\mathrm{bi}}
$$

By matrix expressed:

$$
Q=\mathrm{H}_{b} \mathrm{D}_{b}+I Q_{b}
$$

Where $\mathrm{H}_{\mathrm{b}}$ is row matrix composed of enthalpy of every small turbine. hi-1 is outlet enthalpy of NO. i small boiler, $h_{i-1, i-1}$ is outlet enthalpy of NO. i small boiler $(i=1 \sim n+1) . D_{b}$ is column matrix composed of flow of every small boiler, $\mathrm{D}_{\mathrm{b}}=\left[\mathrm{D}_{\mathrm{b} 1}, \mathrm{D}_{\mathrm{b} 2}, \cdots \mathrm{D}_{\mathrm{b}(\mathrm{n}+1)}\right]^{\mathrm{T}}$. $\mathrm{Q}_{\mathrm{b}}$ is column matrix composed of auxiliary heat of every small boiler $\mathrm{Q}_{\mathrm{b}}=\left[\mathrm{Q}_{\mathrm{b} 1}, \mathrm{Q}_{\mathrm{b} 2}, \cdots \mathrm{Q}_{\mathrm{b}(\mathrm{n}+1)}\right]^{\mathrm{T}}$. $\mathrm{I}=[1,1 \cdots 1]_{\mathrm{n} \times 1}$ is row matrix composed of the $n+11$, Secondary reheat unit just get through each small boiler working fluid parameters of inlet and outlet. Including the working fluid enthalpy and flow in various small boiler.

for each heater to establish the energy and mass balance equation, as follow:

$$
\sum_{j=1}^{i} a_{\mathrm{ij}} D_{j}+Q_{i}=\tau_{i} G_{i}(i=1 \sim \mathrm{n})
$$

By matrix expressed:

$$
\left(\begin{array}{cccc}
a_{11} & & \\
a_{21} & a_{22} & \\
\vdots & \vdots & \ddots \\
a_{\mathrm{n} 1} & a_{n 2} & \cdots & a_{n n}
\end{array}\right)\left(\begin{array}{l}
D_{1} \\
D_{2} \\
\vdots \\
D_{n}
\end{array}\right)+\left(\begin{array}{l}
Q_{1} \\
Q_{2} \\
\vdots \\
Q_{n}
\end{array}\right)=\left(\begin{array}{lll}
\tau_{1} & & \\
& \ddots & \\
& & \tau_{n}
\end{array}\right)\left(\begin{array}{l}
G_{1} \\
G_{2} \\
\vdots \\
G_{n}
\end{array}\right)
$$

Abbreviated as:

$$
A D+Q=\tau G
$$

Where $A$ is thermodynamic system structural matrix, $D$ is nominal amount of exhaust column matrix, $Q$ is column matrix composed of nominal auxiliary heating amount, $\tau$ is diagonal matrix composed of feed water of enthalpy rise, $G$ is column matrix composed of nominal feed water flow of every heater. 


\section{Introduction of Unit Extraction System and calculation results}

In this paper thermal economy calculated unit is $2 \times 660 \mathrm{MW}$ double reheat ultra-supercritical coal-fired units, it is the first case of 600MW secondary level reheat unit in China. The unit has 10 segments extraction, a part of first stage extraction steam entered boiler reheat, a part of third stage extraction steam entered boiler reheat again. In rated conditions, the main steam pressure is $29.2 \mathrm{MPa}$, the main steam temperature is $600{ }^{\circ} \mathrm{C}$, a reheat pressure is $10.14 \mathrm{MPa}$, a reheat temperature is $620{ }^{\circ} \mathrm{C}$, double reheat pressure is $3.196 \mathrm{MPa}$, double reheat temperature is $620{ }^{\circ} \mathrm{C}$. Its extraction diagram as follow:

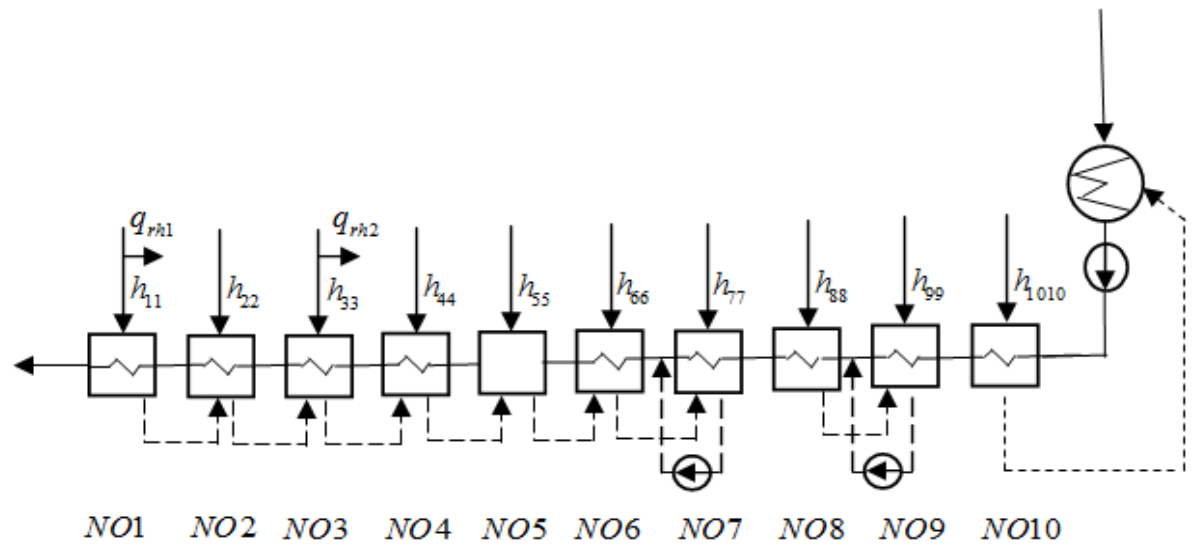

Fig.1. Schematic diagram of double reheat unit extraction

Based on 100\%, 75\% and 50\% working condition, calculation results shown in the following table:

Tab.1. Unit cycle thermal efficiency between single reheat unit and double reheat unit

\begin{tabular}{|c|c|}
\hline 100\%ТНА & $\begin{array}{l}\text { Unit cycle thermal efficiency } \\
\qquad \eta_{t}(\%)\end{array}$ \\
\hline Single Reheat Unit & 47.99 \\
\hline Double Reheat Unit & 50.25 \\
\hline
\end{tabular}

Tab.2. In different conditions unit cycle thermal efficiency between splitting and no splitting

\begin{tabular}{|c|c|c|}
\hline condition & $\begin{array}{c}\text { Unit cycle thermal } \\
\text { efficiency } \boldsymbol{\eta}_{\mathbf{t}} \\
\text { (Splitting) }\end{array}$ & $\begin{array}{c}\text { Unit cycle thermal } \\
\text { efficiency } \boldsymbol{\eta}_{\mathbf{t}} \\
\text { (No splitting) }\end{array}$ \\
\hline 100\%THA & 63.24 & 50.25 \\
\hline $75 \%$ THA & 60.15 & 49.33 \\
\hline $50 \%$ THA & 55.36 & 46.16 \\
\hline
\end{tabular}

As Tab. 1 shown, we can find the double reheat cycle thermal efficiency is $2.26 \%$ higher than single reheat unit; The Tab.2 shows, after high pressure splitting, unit cycle thermal efficiency increased about 10\%, with load decreasing cycle thermal efficiency is declining and Effects of high pressure splitting is also reduced.

\section{Conclusion}

In this paper we utilize the method which is described above, results in the double reheat cycle efficiency unit indeed better than single reheat unit, However, the double reheat unit on the initial 
investment is higher than the single reheat unit and double reheat unit structure is more complex, whether the actual operation of the real economy or resource utilization can achieve balance, require further accounting.

For double reheat units, the effect of high pressure heater splitting is more larger, as a result of 4 high pressure heaters splitting, the extraction of 4 high pressure heaters lose suddenly, more work steam enter the turbine, the unit cycle thermal efficiency improve. Although the turbine acting improves, due to the high pressure heaters splitting make the water temperature drops, after a period of time will gradually increase the working fluid in the heat absorption of the boiler, the unit cycle thermal efficiency will decrease, and gradually decreasing with decreasing load, Therefore, In high-load operation, the operating person should always monitor the water level of high pressure heaters and other parameters whether normal or not, to avoid the impact of high pressure heaters splitting .

\section{References}

[1] The 12th five-year period energy development ideas and strategic focus, Energy observation network, 2010.

[2] Zhiqiang Lv et al. Ultra-supercritical steam turbine materials research, Chinese society for electrical engineering, 2006.

[3] Junjie Yan et al. A method for analysis the economics of a thermal system in a supercritical pressure power unit with double reheat cycles, Proceedings of the CSEE, 24(1), pp.186-190, 2004.

[4] Shufang Zhang et al. Thermal efficiency analysis of double reheat power generation sets with expanding type of energy efficiency distribution matrices. Journal of Power Engineering, 26(3), pp.437-442,2006.

[5] Yunze Li et al. Linear method for the thermal economical analysis of supercritical pressure power plant with double reheat, Proceedings of the CSEE, 22(6),pp.132-136, 2002.

[6] Jiangang Li et al. A study of heat economy calculating model for thermal system in supercritical pressure power unit with second reheat cycles, Turbine Technology, 47(6),pp.425-427,450,2005.

[7] Zhongde Guo et al. Constant-heat equivalent enthalpy drop matrix equation for power unit with double reheat. Journal of North China Electric Power University,40(3),pp.81-85,2013. 